\title{
A simple model of the Arctic Ocean response to annular atmospheric modes
}

\author{
Bob Newton, ${ }^{1}$ L. Bruno Tremblay, ${ }^{1}$ Mark A. Cane, ${ }^{1}$ and Peter Schlosser ${ }^{1}$ \\ Received 25 July 2004; revised 3 November 2005; accepted 19 January 2006; published 15 September 2006.
}

[1] A dynamical mechanism is described that modulates the tilt of the sea-surface height and pycnocline depth between the central Arctic and the continental shelves. A simple analytical model is presented, forced with idealized zonal winds over an idealized, 2-layer, cylinder representing the Arctic Ocean. Ekman transports are linked to sea-surface and pycnocline tilt anomalies and basin-scale circulation in response to an annular wind anomaly. We compare the results to tide gauge data, as well as results from a more realistic numerical simulation and find that the model explains a major fraction of the interannual-to-decade scale sea-surface height anomalies at Arctic coastal tide gauges. The analytical model indicates, for example, that on the order of $10 \mathrm{~cm}$ of the observed rise of about $18 \mathrm{~cm}$ in coastal Arctic sea-surface height between about 1985 and 1993 was probably a response to increased Westerly winds associated with a strong positive phase of the Northern Annular Mode of atmospheric variability. The pycnocline depth anomaly time series from the model is used to calculate implied changes in the outflow of relatively fresh Polar Water to the North Atlantic. The comparisons indicate that the Ekman transport mechanism is important to changes in the export of buoyancy from the Arctic Ocean on seasonal, interannual, and decadal timescales.

Citation: Newton, B., L. B. Tremblay, M. A. Cane, and P. Schlosser (2006), A simple model of the Arctic Ocean response to annular atmospheric modes, J. Geophys. Res., 111, C09019, doi:10.1029/2004JC002622.

\section{Introduction}

[2] We are motivated in this paper by an interest in the exchange of buoyancy between the Arctic Ocean and the North Atlantic. To "zeroth" order, the Arctic Ocean can be thought of as an estuarine embayment of the Atlantic Ocean, with salty (about 34.9 to 35 psu) North Atlantic water flowing in from the south and sinking below a layer of relatively fresh "Polar" water (salinity about 30 to $32.5 \mathrm{psu}$ ). Polar water flows to the North Atlantic in the East Greenland Current and through the straits of the Canadian Arctic Archipelago. This exchange constitutes a flux of buoyancy from the surface Arctic to the surface of the Nordic seas, where it modulates the vertical stratification over the convective gyres that ventilate the deep North Atlantic. In this way, the outflow of fresh water from the Arctic plays a role in the meridional overturning circulation (MOC) and, through the MOC, in the global climate. In what follows we describe a simple model of the Arctic and how changes in the large-scale wind patterns can change the sea-surface height (SSH) and the depth of the bottom of the pycnocline at the periphery of the Arctic Ocean. The implication is that when the SSH is high and the mixed layer thick at the Arctic periphery, the buoyant outflow will increase, and vice versa.

\footnotetext{
${ }^{1}$ Lamont-Doherty Earth Observatory of Columbia University of New York, Palisades, New York, USA.

Copyright 2006 by the American Geophysical Union. 0148-0227/06/2004JC002622
}

[3] The relatively fresh layer overlying the deep basins of the Arctic Ocean is typically ten to several tens of meters thick and grades into a halocline that constitutes nearly all of the vertical stratification in the water column [see, e.g., Environmental Working Group (EWG), 1998]. The base of the halocline is generally 150 to 200 meters deep, and attains its deepest levels in the "Beaufort Gyre", an anticyclonic feature in the Canadian Basin [see, e.g., Swift et al., 1997]. Relative to the salinity of all Arctic Ocean water (about 34.8), the upper waters of the Arctic Ocean contain a fresh water "excess" on the order of $60,000 \mathrm{~km}^{3}$ (calculated from EWG [1998]; also, see analysis in Aagaard and Carmack [1989]). This would be sufficient to form a layer of pure fresh water about $6 \mathrm{~m}$ thick covering the 10 million square kilometer area of the deep basins of the Arctic Ocean. In addition, there is an annual average of about $17,000 \mathrm{~km}^{3}$ of fresh water stored in Arctic sea-ice [Aagaard and Carmack, 1989]. Figure 1 displays the horizontal distribution of the time-averaged freshwater anomaly, relative to a reference salinity of 34.8 , in the upper 2000 meters of the Arctic water column.

[4] The Arctic surface waters are maintained at a relatively low salinity by river runoff, the inflow of relatively fresh Pacific surface water through Bering Strait, and local precipitation [Aagaard and Carmack, 1989; Yang, 1999; Schlosser et al., 2002]. The fresh water inflows are difficult to monitor in any precise way, and are variable in time, but we can give rough estimates of their sizes. Terrestrial discharge, including major rivers and diffuse sources (streams, groundwater leakage, melting tundra) supplies about $4,300 \mathrm{~km}^{3}$ per 


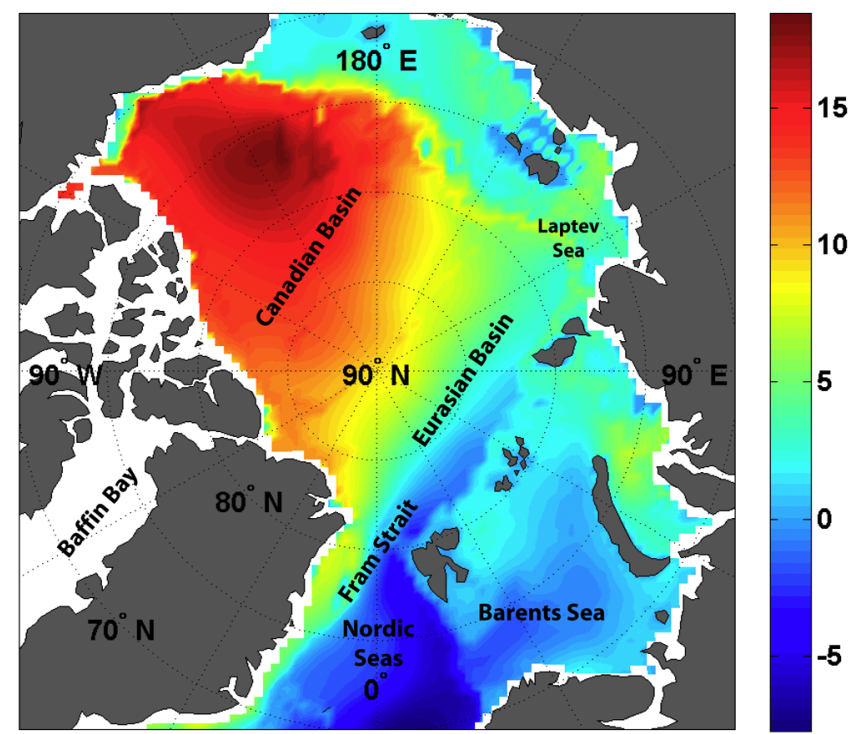

Figure 1. Freshwater content, relative to 34.8, from the Environmental Working Group climatology. Values are meters of freshwater that would have to be added to water of salinity 34.8 to create the observed climatological salinities in the upper 2000 meters of the water column.

year [Shiklomanov et al., 2000; R-Arctic Net database]. The inflow through the main channels of Bering Strait averages about $0.85 \mathrm{~Sv}$ (Sverdrup $=10^{6} \mathrm{~m}^{3} / \mathrm{s}$ ), and is about $2 \pm$ 0.5 psu less saline than the North Atlantic inflow, which is equivalent to adding about $1,700 \mathrm{~km}^{3}$ of pure fresh water to the Bering Strait area each year [Aagaard and Carmack, 1989; Roach et al., 1995]. In addition, the Alaskan Coastal Current and seasonal influxes of sea ice through Bering Strait add about another $800 \mathrm{~km}^{3}$ [Woodgate and Aagaard, 2005]. Average precipitation rates are about $23.7 \mathrm{~cm}$ [Yang, 1999], of which about $9.9 \mathrm{~cm}$ sublimates [Dery and Yau, 2002] and $2.3 \mathrm{~cm}$ ablates through wind action and is sublimated in the atmosphere. These estimates are in good agreement with net P-E estimates from satellites (13 to $15 \mathrm{~cm}$, depending on the area considered [Groves and Francis, 2002]). We take a rough net accumulation from precipitation of approximately $12 \mathrm{~cm}$, or about $1,200 \mathrm{~km}^{3}$ over the deep Arctic. The annual supply of fresh water from all sources is thus on the order of $7,800 \mathrm{~km}^{3}$ per year, which represents about one tenth of the freshwater "reservoir" in the upper ocean and ice over the central Arctic Ocean.

[5] At steady state, the average freshwater flux out of the Arctic Basin must balance the supply. However, over any season, year or decade the inflows may be larger or smaller than the outflows, leading to accumulation or depletion of the freshwater reservoir. In this contribution we describe a mechanism through which the large-scale wind patterns modulate freshwater export from the Arctic surface waters, thereby changing the export of buoyancy from the Arctic Ocean to the Nordic seas and Baffin Bay.

[6] We begin, in section 2, with a brief overview of the problem. In section 3 we describe our conceptual model and present an analytic solution. We consider a simple model: purely zonal surface stresses, representing an idealized Northern Annular Mode, forcing a cylindrical basin, repre- senting an idealized Arctic Ocean. The model is formulated in such a way that a family of solutions is found, ranging from the purely barotropic to the purely baroclinic case. Using standard formulations for wind stress, Ekman boundary layers and geostrophic balance, we link the sea-level pressure anomaly to the tilts of the sea-surface height (SSH) and of the pycnocline. The analytic model is solved, in the first instance using a zonal wind-stress anomaly that is scaled to the observed amplitude of a shift in zonal wind speeds between about 1980 and 1991, a period during which indices of the Northern Annular Mode increased substantially. The model results for this anomaly are compared with the output of a high-resolution ice-ocean general circulation model. We then force the model with timevarying wind-stress anomalies between 1949 and 2001. In section 4, those results are compared with observed seasurface height anomalies from coastal tide gauges. The change in depth of the pycnocline as a result of the surface forcing is calculated, and the pycnocline depth anomaly is used, in section 5 , to calculate the implied change in freshwater flux from the Arctic Ocean to the North Atlantic. Section 6 is a discussion of the simplifications that are inherent in this highly idealized approach. We conclude, section 7 , by relating the results to some of the current issues in Arctic Change research.

\section{Background}

[7] In a rotating system, in the absence of surface stresses, buoyant inflows at the outer boundary of a basin will tend to remain trapped at the edge, flowing around the boundary in the same direction as the basin's rotation. This behavior is shown in elementary laboratory demonstrations [e.g., Hunkins and Whitehead, 1992]. It has also been studied in lakes and along many coastlines, including the Arctic Ocean [Weingartner et al., 1999]. Light water on a continental shelf will tend to remain on the shelf, and can travel for thousands of kilometers along the coast with relatively little mixing out into the waters over the deep basin. This is because in a rotating system the pressure gradients between light inflows at the edges and saltier water offshore encourage along-shore flow. One might therefore expect the fresh surface water entering the Arctic Ocean to flow along the margins and reach the outflows (Fram Strait and the CAA) without crossing the deep Eurasian and Canadian basins. In this context, it is unexpected that such a large pool of fresh, buoyant water is sustained in the surface waters of the Beaufort Gyre (Figure 1). A certain amount of cross-shelf transport of freshwater is accomplished by eddies generated along the salinity front offshore of the fresh coastal current [Weingartner et al., 1999]. However, eddy transports cannot account for the maximum in freshwater over the Canadian Basin. To focus such high concentrations of freshwater in the Beaufort Gyre the wind stresses must play a dominant role.

[8] Several authors have investigated the link between wind-stress curl and the large-scale circulation in the Arctic. For example, Nikiforov et al. [1969a] found that relatively cyclonic (anticyclonic) winds corresponded to relatively shallow (deep) convection, which implied relatively low (high) vertical heat fluxes from the Atlantic layer to the surface. They also found [Nikiforov et al., 1969b] that 
relatively cyclonic winds led to a deeper penetration of Atlantic inflow to the Arctic. Gudkovich [1961] demonstrated an annual cycle between these two types of circulation: relatively cyclonic summer circulation bows the sea-surface upward over the shelves and downward over the deep basin; with the isopycnals of the halocline compensating in the other direction; and vice versa during the relatively anticyclonic winter regime. Treshnikov [1971] found that these cyclonic and anticyclonic tendencies were also observed on interannual timescales with duration of 6 to 8 years.

[9] The early Russian observations and analyses [e.g., Nikiforov et al., 1966, 1969a, 1969b; Treshnikov, 1971] focused on the Eurasian region between the eastern Barents and the Laptev Seas, where the Soviet Union conducted regular air- and patrol-boat-based transects. More recently, Hunkins and Whitehead [1992] conducted laboratory experiments with a divided rotating tank, showing that a change of sign in the wind-stress curl between two basins would move light waters from one basin to the other and from the periphery to the center of the accumulating basin. The normal situation is cyclonic winds over the Nordic Seas extending, especially in the winter, into the Barents Sea and the southern Eurasian Basin, and anticyclonic winds over the Canadian Basin. Hunkins and Whitehead showed that the wind-stress curl gradient could explain the high concentration of freshwater over the Canadian Basin. Proshutinsky and Johnson [1997] identified relatively cyclonic and relatively anticyclonic circulation regimes in a barotropic Arctic Ocean model driven with realistic winds. They describe the "Arctic Ocean Oscillation" as a coupled atmosphere-ocean mode of variability with about a 14 -year period (commensurate with Treshnikov's 6-8 year regimes): In the anticyclonic regime, high sea level pressure over the Beaufort Gyre dominates the surface winds while the ocean surface is high over the Gyre and low over the shelves. In the cyclonic regime, low pressure over the Eastern Eurasian Basin dominates the surface winds while the ocean surface is low over the Central Arctic and high over the shelves. The oscillation tends toward regime behavior because there are positive feedbacks: high (low) SLP corresponds to anticyclonic (cyclonic) wind stress which leads to convergent (divergent) conditions in the pack ice which decreases (increases) the heat flux from the ocean to the atmosphere, reinforcing the high (low) pressure trend. In their barotropic model, the winds are specified, and the "switch" between the two regimes is ascribed to changes in the relative positions and strengths of the Icelandic Low and the Siberian High.

[10] In a high-resolution ice-ocean model driven by realistic winds from the 1979-1997 ECMWF Re-Analysis, Newton and co-workers found a spatial pattern of sea surface height (SSH) anomalies similar that found by Proshutinsky and Johnson [1997] [Newton, 2001]. They ascribed the changes to an ocean response to large-scale atmospheric patterns, related to the Northern Annular Mode (NAM) rather than a coupled Arctic mode of variability. The physics underlying the phenomenon is straightforward: a positive phase of the NAM involves a low SLP anomaly in the Arctic and a high SLP anomaly at midlatitudes. That pressure gradient is associated with more cyclonic winds

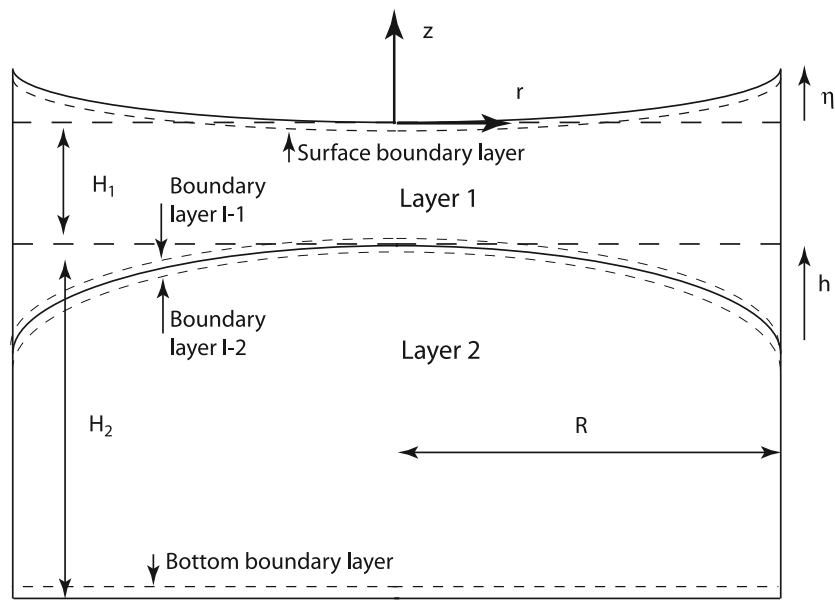

Figure 2. Side view of the model setup, with surface and pycnocline depth displacements from a cyclonic wind-stress anomaly shown.

over the Arctic. More cyclonic winds drive Ekman divergence in the ocean surface, which will tend to move water from the central basin to the shelves and coastal areas, lowering SSH in the center and raising it over the shelves and, especially, along the coasts. Below we use our simple model to investigate this straightforward dynamics.

\section{Analytic Model Description}

[11] In the Arctic Ocean the meridional gradient of the Coriolis effect $(\beta)$ is small, so spatial variations in in potential vorticity there are dominated by the basin's bathymetry. This raises the possibility that currents guided by the continental slope that nearly surrounds the Arctic Basin may be relatively easy to excite, and may constitute natural modes of variability in Arctic circulation. The goal of this section is to construct a simple, analytical model of how such a mode might be driven by surface stresses analogous to those discussed above. We choose the simplest model that includes rotation and stratification: a thin, rotating, twolayered disk (Figure 2). The upper layer, Layer 1, is slightly lower in density (on the order of 2 parts per thousand) and is much thinner than the lower layer, Layer 2.

[12] We are interested in the large-scale, slowly evolving behavior, so the transient evolution of the model will not be investigated. The interior of each of the two layers is considered to be in geostrophic balance, forced by horizontal pressure gradients. Each layer has upper and lower boundary layers. The upper boundary layer of Layer 1 is coupled by friction to the atmosphere and the bottom boundary layer of Layer 2 is frictionally coupled to the ocean floor. Layers 1 and 2 are coupled to each other by "interface" boundary layers. Sidewall friction is ignored, since the aspect ratio of depth-to-width in the Arctic Ocean is on the order of $1: 1000$.

[13] The model is formulated in cylindrical coordinates $(\mathrm{r}, \theta, \mathrm{z})$ with the vertical coordinate positive upward from the atmosphere-ocean interface. A positive phase of the Northern Annular Mode (NAM) corresponds to increased westerly winds, which is a positive anomaly in cylindrical 
coordinates ( $\theta$ is positive eastward). When the surface stress driving the upper Ekman layer is cyclonic, the Ekman drift is toward the outer wall, causing a rise in sea-surface height there, and a corresponding drop at the center. This seasurface tilt initiates a pressure-driven, zonal flow eastward in both density layers. However, due to its lower mass the upper layer accelerates more quickly, and there is a vertical shear in the velocities, which leads to shear stress at the interface between the two density layers. In a manner analogous to the frictional layers at the top and bottom of the fluid column, the shear stress will lead, in a rotating system, to drift inward in the bottom of the upper density layer and outward in the upper boundary of the lower density layer. At the bottom of the lower layer, a bottom Ekman layer develops. Once the system is spun up, the only sink for the energy input at the upper surface by wind stress is frictional loss at the bottom. In the model, there is no creation of potential energy by mixing across the interface.

[14] The two layers will continue to accelerate until the Ekman layers come into balance: the lower density layer must move eastward (for westerly wind) quickly enough to dissipate the input of energy from the winds above. Since there is no cross-interface mixing, the difference in velocities between the two density layers must be sufficient for the Ekman drift in the boundary layers at the density interface to match those at the top and bottom of the whole water column. At steady state, the two density layers will be traveling in the same direction, but the upper layer will be traveling faster. For this to be the case, the interface between the two will have to tilt in the opposite direction as the top surface. For westerly winds, the top surface will tilt up from the center to the outer boundary, and the interface between the layers will tilt down. Thus, westerly winds will increase the thickness of the upper layer at the outer edge of the disk. Easterly winds will have the opposite affect. Given a value for the zonal wind stress, the Ekman layer balances can be used to determine the interior velocities of the two density layers as well as the tilts of both the sea surface and the density interface.

[15] Consider a two-layered disk of fluid, in solid body rotation at a constant rate, $\Omega$. Assume that the upper layer, Layer 1, is slightly lighter, for example two to three parts per thousand, and is much thinner, for example 1/20th the thickness, compared with the lower layer, Layer 2. Assume the two layers to be immiscible: fluid cannot cross the interface between them. Suppose that the surface of the fluid is subjected to a zonal stress, $\tau_{\text {top }}=\left(\tau_{r, \text { top }}, \tau_{\theta, \text { top }}\right)=\left(0, \tau_{\theta, \text { top }}\right)$.

[16] See Figure 2 for definitions of variables. We will use bold type for vectors and normal weight type for scalars; subscripts $r, \theta$ and $z$ will always designate the coordinate system; $z=0$ at the top of the fluid surface and is negative downward; subscripts " 1 " and " 2 " will designate the upper and lower density surfaces, respectively; subscripts "top" and "bottom" will designate the upper surface of Layer 1 and the lower surface of Layer 2, respectively; subscripts "I1" and "I2" will designate the interior surfaces, at the interface between the two layers, from the perspective of layers 1 and 2, respectively; subscripts " $G$ " and " $E$ " will designate the interior (geostrophic) and boundary layer (Ekman) flows, respectively; $\mathrm{H}_{1}$ and $\mathrm{H}_{2}$ will refer to the thicknesses of Layers 1 and 2 in solid body rotation, and $\eta$ and $\mathrm{h}$ will refer to the displacements from their unperturbed positions of the upper surface and the interlayer interface, respectively. Capital letters indicate the vertical integrals of their lower case counterparts. Thus, for example, $\mathrm{U}_{\mathrm{E}, \mathrm{I} 2, \mathrm{r}}$ is the vertical integral of the radial Ekman velocity in the upper boundary layer of the lower density layer. This notation is similar to that used by Gill [1982, chapter 9].

[17] The symmetry of the tank and the forcing implies that there can be no zonal gradient in surface or interfacial height anomaly ( $\eta$ or $h$ ) and therefore no radial flow in the geostrophic interior. Using cylindrical coordinates the equations for the two geostrophic interior flows are:

$$
\begin{gathered}
f u_{G, \theta, 1}=g \frac{\partial \eta}{\partial r} \\
f u_{G, \theta, 2}=g \frac{\rho_{1}}{\rho_{2}} \frac{\partial \eta}{\partial r}+g \frac{\rho_{2}-\rho_{1}}{\rho_{2}} \frac{\partial h}{\partial r}=g \frac{\rho_{1}}{\rho_{2}} \frac{\partial \eta}{\partial r}+g^{\prime} \frac{\partial h}{\partial r}
\end{gathered}
$$

where $\mathrm{g}$ is the gravitational constant, and g' is the "reduced" gravity. In each of the four Ekman layers:

$$
\begin{aligned}
& f u_{E, \theta}=\nabla \bullet \kappa \nabla u_{E, r} \approx k_{z} \frac{\partial^{2} u_{E, r}}{\partial z^{2}} \\
& f u_{E, r}=\nabla \bullet \kappa \nabla u_{E, \theta} \approx k_{z} \frac{\partial^{2} u_{E, \theta}}{\partial z^{2}}
\end{aligned}
$$

where internal stresses away from the boundary are considered to be negligible; stresses in the boundary layer are assumed to be proportional to the component of the Laplacian $\left(\nabla^{2}\right)$ perpendicular to the boundary; $\mathrm{k}_{\mathrm{z}}$ is the vertical viscosity coefficient; and, as noted above, side-wall friction has been ignored since the aspect ratio of the depth to the width relevant to the Arctic basin is small.

[18] At the top and bottom of the water column, equations (3) and (4) are solved with the boundary conditions:

$$
\begin{gathered}
\frac{\partial \mathbf{u}_{E, \text { top }}(r, \theta, \eta)}{\partial z}=\frac{\boldsymbol{\tau}_{\text {top }}}{\rho k_{z, \text { top }}} \\
\lim _{z \rightarrow-\infty}\left(\mathbf{u}_{E, \text { top }}(r, \theta, z)\right)=0 \\
\mathbf{u}_{E, \text { bottom }}\left(r, \theta,-\left(H_{1}+H_{2}\right)\right)=-\mathbf{u}_{G, 2}(r, \theta) \\
\lim _{z \rightarrow \infty}\left(\mathbf{u}_{E, \text { bottom }}(r, \theta, z)\right)=0
\end{gathered}
$$

where $\rho$ is the water density and $\tau$ is the surface stress at the top of the fluid. The solutions are the well-known upper and lower Ekman spirals. In the upper layer:

$$
\begin{aligned}
& u_{E, \theta, t o p}=\frac{\sqrt{2}}{\rho_{1} f d} e^{(z-\eta) / d} \tau_{\theta, \text { top }} \cos \left(\frac{z-\eta}{d}-\frac{\pi}{4}\right) \\
& u_{E, r, t o p}=\frac{\sqrt{2}}{\rho_{1} f d} e^{(z-\eta) / d} \tau_{\theta, \text { top }} \sin \left(\frac{z-\eta}{d}-\frac{\pi}{4}\right)
\end{aligned}
$$


where $d$ is the length-scale of the boundary layer:

$$
d=\left(2 k_{z} / f\right)^{1 / 2}
$$

The volume transport in the top boundary layer is to the right of the surface stress:

$$
\mathbf{U}_{E, \text { top }} \equiv \int_{-\infty}^{\eta} \mathbf{u}_{E, \text { top }} d z=\frac{1}{\rho_{1} f}\left(\tau_{\theta, \text { top }},-\tau_{r, \text { top }}\right)=\frac{1}{\rho_{1} f}\left(\tau_{\theta, \text { top }}, 0\right)
$$

At the bottom, the Ekman layer is driven by the interior velocity:

$$
\begin{aligned}
& u_{E, \theta, \text { bottom }}=-u_{G, 2} e^{\left(-z-H_{1}-H_{2}\right) / d} \cos \left(\frac{z-H_{1}-H_{2}}{d}\right) \\
& u_{E, \text {, }, \text { ottom }}=-u_{G, 2} e^{\left(-z-H_{1}-H_{2}\right) / d} \sin \left(\frac{z-H_{1}-H_{2}}{d}\right)
\end{aligned}
$$

From this velocity profile, we can calculate the bottom stress:

$$
\begin{aligned}
\boldsymbol{\tau}_{\text {bottom }} & =\left.\rho_{2} k_{z, \text { bottom }} \frac{\partial \mathbf{u}}{\partial z}\right|_{z=-\left(H_{1}+H_{2}\right)} \\
& =\rho_{2}\left(\frac{k_{z, \text { bottom }} f}{2}\right)^{1 / 2} u_{G, \theta, 2}(-1,-1)
\end{aligned}
$$

which is $135^{\circ}$ to the left of the direction of the interior flow in Layer 2. The factor $\left(k_{\mathrm{z}} \mathrm{f} / 2\right)^{1 / 2}=\mathrm{k}_{\mathrm{z}} / \mathrm{d}$ emerges as a coupling coefficient, relating the bottom stress to the interior flow. The volume transport in the bottom boundary layer is:

$$
\begin{aligned}
\mathbf{U}_{E, \text { bottom }} & \equiv \int_{-\left(H_{1}+H_{2}\right)}^{\infty} \mathbf{u}_{E, \text { bottom }} d z=\frac{1}{\rho_{2} f}\left(\tau_{\theta, \text { bottom }},-\tau_{r, \text { bottom }}\right) \\
& =\left(\frac{k_{z, \text { bottom }}}{2 f}\right)^{1 / 2} u_{G, \theta, 2}(-1,1)
\end{aligned}
$$

[19] At the interface between layers 1 and 2, we infer the vertical transfer of momentum between layers by requiring that the velocity be continuous at the interface. Then the boundary layers, I1 and I2, allow for the adjustment of the velocity in each layer from its geostrophic value in the interior to an intermediate value at the interface. Taking that intermediate velocity to be the average of the upper and lower interior velocities: $\mathbf{u}\left(-H_{1}+h\right)=\mathbf{u}_{G}\left(-H_{1}+h\right)+$ $\mathbf{u}_{E}\left(-H_{1}+h\right)=\left(\mathbf{u}_{G, 1}+\mathbf{u}_{G, 2}\right) / 2$, the boundary conditions will be:

$$
\begin{gathered}
\mathbf{u}_{E, I 1}\left(r, \theta,-H_{1}+h\right)=\frac{\left(\mathbf{u}_{G, 2}-\mathbf{u}_{G, 1}\right)}{2}=\left(0, \frac{\left(u_{G, \theta, 2}-u_{G, \theta, 1}\right)}{2}\right) \\
\mathbf{u}_{E, I 2}\left(r, \theta,-H_{1}+h\right)=\frac{\mathbf{u}_{G, 1}-\mathbf{u}_{G, 2}}{2}=\left(0, \frac{u_{G, \theta, 1}-u_{G, \theta, 2}}{2}\right) \\
\lim _{z \rightarrow \infty}\left(\mathbf{u}_{E, I 1}(r, \theta, z)\right)=\lim _{z \rightarrow-\infty}\left(\mathbf{u}_{E, I 2}(r, \theta, z)\right)=0
\end{gathered}
$$

[20] The solutions for the velocity and stress are similar to those in the bottom boundary layer, and the volume transports are:

$$
\begin{aligned}
\mathbf{U}_{E, I 1} & \equiv \int_{-H_{1}}^{\infty} \mathbf{u}_{E, I 1} d z=\frac{1}{\rho_{1} f}\left(\tau_{\theta, I 1},-\tau_{r, I 1}\right) \\
& =\left(\frac{k_{z, I}}{2 f}\right)^{1 / 2} \frac{u_{G, \theta, 2}-u_{G, \theta, 1}}{2}(-1,1)
\end{aligned}
$$

$$
\mathbf{U}_{E, I 2} \equiv \int_{-\infty}^{-H_{1}} \mathbf{u}_{E, I 2} d z=\left(\frac{k_{z, I}}{2 f}\right)^{1 / 2} \frac{u_{G, \theta, 1}-u_{G, \theta, 2}}{2}(1,-1)
$$

where we have assumed that the viscosity coefficient, $\mathrm{k}_{\mathrm{z}, \mathrm{I}}$ is the same immediately above and below the interface.

[21] At steady state the radial transport is entirely within the boundary layers, and the vertical integral of this transport must vanish within each density layer:

$$
\mathbf{U}_{E, r, t o p}+\mathbf{U}_{E, r, I 1}=0
$$

$$
\begin{gathered}
\left(\frac{k_{z, I}}{2 f}\right)^{1 / 2} \frac{u_{G, \theta, 2}-u_{G, \theta, 1}}{2}=-\frac{\tau_{\theta, \text { top }}}{\rho_{1} f} \\
\mathbf{U}_{E, r, I 2}+\mathbf{U}_{E, r, \text { bottom }}=0 \\
\left(\frac{k_{z, I}}{2 f}\right)^{1 / 2} \frac{u_{G, \theta, 1}-u_{G, \theta, 2}}{2}=\left(\frac{k_{z, \text { bottom }}}{2 f}\right)^{1 / 2} u_{G, \theta, 2} \\
u_{G, \theta, 1}=u_{G, \theta, 2}\left(1+2\left(\frac{2}{u_{G, \theta, 2}=\left(\frac{k_{z, \text { bottom }}}{k_{z, I}}\right)^{1 / 2}}\right)^{1 / 2} \frac{\tau_{\theta, \text { top }}}{\rho_{1}}\right. \\
=\left(\frac{2}{k_{z, \text { bottom }}}\right)^{1 / 2} \frac{\tau_{\theta, \text { top }}}{\rho_{1}}\left(1+2\left(\frac{k_{z, \text { bottom }}}{k_{z, I}}\right)^{1 / 2}\right)
\end{gathered}
$$

Equation (27) describes the vertical shear of the geostrophic flow. The barotropic flow is:

$$
\begin{aligned}
\frac{H_{1} u_{G, 1, \theta}+H_{2} u_{G, 2, \theta}}{H_{1}+H_{2}}= & \frac{1}{H_{1}+H_{2}}\left(H_{1}\left(\frac{2}{\text { fk } k_{z, \text { bottom }}}\right)^{1 / 2}\right. \\
& \cdot \frac{\tau_{\theta, \text { top }}}{\rho_{1}}\left(1+2\left(\frac{k_{z, \text { bottom }}}{k_{z, I}}\right)^{1 / 2}\right) \\
& \left.+H_{2}\left(\frac{2}{\text { fkz,bottom }}\right)^{1 / 2} \frac{\tau_{\theta, \text { top }}}{\rho_{1}}\right) \\
= & \frac{\tau_{\theta, \text { top }}}{\left(k_{z, \text { bottom }}\right)^{1 / 2}}\left(\frac{2}{f}\right)^{1 / 2} \frac{1}{\rho_{1}\left(H_{1}+H_{2}\right)} \\
& \cdot\left(H_{1}\left(1+2\left(\frac{k_{z, \text { bottom }}}{k_{z, I}}\right)^{1 / 2}\right)+H_{2}\right)
\end{aligned}
$$


The strength of the barotropic flow is proportional to the ratio of surface stress at the top of the fluid and the square root of the vertical viscosity coefficient at the bottom. The ratio between the upper and lower geostrophic velocities depends on the ratio of the vertical viscosity coefficient at the bottom to the coefficient at the interlayer interface: $\frac{u_{G, \theta, 1}}{u_{G, \theta, 2}}=\left(1+2\left(\frac{k_{z, \text { botom }}}{k_{z, I}}\right)^{1 / 2}\right)$. If $\mathrm{k}_{\mathrm{z}, \mathrm{I}} \gg \mathrm{k}_{\mathrm{z}, \text { bottom }}$, the system is essentially barotropic, whereas if the opposite is true, then the circulation is dominated by the upper layer flow. These results are not surprising. Momentum is imparted to the fluid by the stress at the top. Ultimately, the only sink for this input is through stress at the bottom. The fluid will accelerate until the velocity at the bottom is sufficient for the bottom stress to balance the surface stress. The bottom viscosity coefficient represents our parameterization of the bottom stresses, and effectively sets the velocity required in the lower layer to create enough bottom stress to balance the surface stress at the top. In our simple 2-layer system, the only way for momentum to be transmitted from the upper layer to the lower one is through the stress at the interface between them. The efficiency of this transfer is parameterized by the vertical viscosity coefficient there. Thus, the ratio of $\mathrm{k}_{\mathrm{z}, \mathrm{I}}$ and $\mathrm{k}_{\mathrm{z} \text {,bottom }}$ determines how great the difference between the upper and lower velocities must be for the surface stress to be transferred downward and removed at the bottom.

[22] We can use the expressions for geostrophic velocities from (26) and (27) in equations (1) and (2) to describe the steady-state deformations of the surface and the interface ( $\eta$ and $h$ ) in response to changes in the stress applied at the surface.

$$
\frac{\partial \eta}{\partial r}=\frac{f u_{G, \theta, 1}}{g}=\frac{\tau_{\theta, \text { top }}}{g}\left(\frac{2 f}{k_{z, \text { bottom }}}\right)^{1 / 2} \frac{1}{\rho_{1}}\left(1+2\left(\frac{k_{z, \text { bottom }}}{k_{z, I}}\right)^{1 / 2}\right)
$$

$$
\begin{aligned}
\frac{\partial h}{\partial r} & =\frac{f u_{G, \theta, 2}-g \frac{\rho_{1}}{\rho_{2}} \frac{\partial \eta}{\partial r}}{g^{\prime}} \\
& =\frac{\tau_{\theta, t o p}}{g^{\prime}}\left(\frac{2 f}{k_{z, \text { bottom }}}\right)^{1 / 2}\left(\frac{1}{\rho_{1}}-\frac{1}{\rho_{2}}\left(1+2\left(\frac{k_{z, \text { bottom }}}{k_{z, I}}\right)^{1 / 2}\right)\right)
\end{aligned}
$$

[23] We are interested in modeling the response of the Arctic to the Northern Annular Mode, so we begin with a symmetrical wind-stress pattern, varying linearly from the center of the model to the boundary:

$$
\begin{gathered}
\tau_{\theta, \text { top }}=2 \tau \mathrm{r} / \mathrm{R} \\
\tau_{r, \text { top }}=0 ;
\end{gathered}
$$

where $\left(\tau_{\theta, \text { top }}, \tau_{\text {rtop }}\right)=\tau_{\text {top }}$ is the stress at the upper surface, $\mathrm{r}$ is the radial coordinate, from the center of the disk, $\mathrm{R}$ is the radius of the basin, and $\tau$ is the average stress along a radius. We want to represent the observed strength of the annular mode by setting the value of the average surface stress, $\tau$, to a function of the pressure anomaly between the North Pole and the southern boundary of the Arctic. We use a bulk formula for the stress as a function of the wind, and relate the wind to the sea-level pressure gradient, to get the average wind stress $\tau$ :

$$
\tau=c_{a o} \rho_{a i r} \cos (\alpha) \operatorname{sign}\left(u_{\theta}\right)\left\|\mathbf{u}_{\text {air }}\right\|^{2} \approx \frac{c_{a o} \cos (\alpha) \delta p|\delta p|}{R^{2} f^{2} \rho_{\text {air }}}
$$

where $c_{a o}$ is a drag coefficient, $\rho_{\text {air }}$ is the density of air, $\mathbf{u}_{\text {air }}$ is the geostrophic wind associated with an annular pressure anomaly, $\alpha$ is the turning angle, which represents the difference between the direction of the geostrophic wind and the direction of the surface stress, and $\delta p$ is the SLP difference between the center of the basin and the edge, over the radial distance R. Note that the turning angle implies a radial stress component, resulting in an azimuthal component to the vertically integrated volume transport. However, given the symmetry of the basin, that would not affect the deformations of the surface and interface, and would therefore not change the interior pressure-driven flows. In the real world, neither the annular mode nor the Arctic bathymetry is perfectly annular. A more detailed model would compare the stream lines of the wind stress anomaly with isobaths of the Arctic shelf-break, but that is beyond the scope of our simple calculation. (See Nost and Isachsen [2003] for a treatment of the time-averaged response in a barotropic model of the Arctic that includes realistic isobaths and mean wind stress directions.)

[24] We can now substitute equation (33) in equations (29) and (30) to get the surface and interface deformations as a function of the annular mode pressure gradient:

$$
\frac{\partial \eta}{\partial r}=\frac{c_{a o} \cos (\alpha) \delta p|\delta p|}{g R^{2} f^{3 / 2} \rho_{\text {air }} \rho_{1}}\left(\frac{2}{k_{z, \text { bottom }}}\right)^{1 / 2}\left(1+2\left(\frac{k_{z, \text { bottom }}}{k_{z, I}}\right)^{1 / 2}\right) \frac{2 r}{R}
$$

$$
\begin{aligned}
\frac{\partial h}{\partial r}= & \frac{c_{a o} \cos (\alpha) \delta p|\delta p|}{g^{\prime} R^{2} f^{3 / 2} \rho_{\text {air }}}\left(\frac{2}{k_{z, \text { bottom }}}\right)^{1 / 2} \\
& \cdot\left(\frac{1}{\rho_{1}}-\frac{1}{\rho_{2}}\left(1+2\left(\frac{k_{z, \text { bottom }}}{k_{z, I}}\right)^{1 / 2}\right)\right) \frac{2 r}{R}
\end{aligned}
$$

To estimate the degree of sea-surface tilt, we set the seasurface height anomaly to zero at the center of the basin, and integrate radially, from 0 to $\mathrm{R}$ :

$$
\Delta \eta=\frac{c_{a o}}{k_{z, \text { bottom }}^{1 / 2}} \frac{1}{\rho_{1}}\left(1+2\left(\frac{k_{z, \text { bottom }}}{k_{z, I}}\right)^{1 / 2}\right) \frac{2^{1 / 2}}{f^{3 / 2}} \frac{\cos (\alpha)}{g R \rho_{\text {air }}} \delta p|\delta p|
$$

$\Delta h=\frac{c_{a o}}{k_{z, \text { bottom }}^{1 / 2}}\left(\frac{1}{\rho_{1}}-\frac{1}{\rho_{2}}\left(1+2\left(\frac{k_{z, \text { bottom }}}{k_{z, I}}\right)^{1 / 2}\right)\right) \frac{2^{1 / 2}}{f^{3 / 2}} \frac{\cos (\alpha)}{g^{\prime} R \rho_{\text {air }}} \delta p|\delta p|$

The parameters R, f, g, $\rho_{1}, \rho_{2}$ and $\rho_{\text {air }}$ are physical parameters of the Arctic system that define the scales of the model. $\delta \mathrm{P}$ is drawn from the observed trend of wind forcing over the Arctic surface. $\alpha$ can be between about 0 and 45 degrees, depending on local winds and surface 
conditions, but 25 degrees is a value that is widely used in modeling Arctic atmosphere-ocean interactions. Two free parameters emerge in formulas (36) and (37), the ratios $\frac{c_{a o}^{2}}{k_{z, \text { bottom }}}$ and $\frac{k_{z, I}}{k_{z, \text { bottom }}}$. The elements are drag or viscosity coefficients that quantify the efficiency with which momentum is transferred across the several boundaries in the system. For a given value of ocean-atmosphere drag coefficient, the bottom viscosity sets the depth-mean velocity, while the viscosity in the pycnocline sets the ratio of upper to lower layer velocities.

[25] If the sea-level pressure gradient, $\delta \mathrm{P}$, from the center to the outer edge is positive, then the sea-surface will rise from the center toward the "coastline", and the interior flow in the disk will be positive as well, in a cyclonic direction around the basin. $\delta \mathrm{P} / \delta \mathrm{r}<0$ will reverse both the $\mathrm{SSH}$ anomaly and the flow.

[26] Stigebrandt [1981], Bjork [1989], and Hunkins and Whitehead [1992] modeled the outflow of freshwater from the Arctic to the North Atlantic by analogy with estuarine flow. Relatively fresh Arctic surface waters play the role of runoff in the estuary, flowing outward over the inflow of denser, more saline, North Atlantic waters. The main dynamical difference is that the "mouth" of the Arctic estuary, composed of Fram, Nares and McClure straits, is deep and wide enough that bottom friction does not control the rate of exchange. Rather, the balance in the straits will be geostrophic, and the exchange will be controlled by the density contrast between the Arctic surface waters (our Layer 1) and the North Atlantic, and by the thickness of the layer above the Arctic pycnocline.

[27] Both the sea-surface tilt and the interface tilt will affect the Layer-1 thickness that is exposed to the outer edge of the disk, representing the Arctic-North Atlantic boundary. For the baroclinic case, most of the thickness anomaly will be in the interface height:

$$
\begin{aligned}
\frac{\Delta h}{\Delta \eta} & =\frac{g}{g^{\prime}} \frac{\left(\frac{1}{\rho_{1}}-\frac{1}{\rho_{2}}\left(1+2\left(\frac{k_{z, \text { bottom }}}{k_{z, I}}\right)^{1 / 2}\right)\right)}{\frac{1}{\rho_{1}}\left(1+2\left(\frac{k_{z, \text { botom }}}{k_{z, I}}\right)^{1 / 2}\right)} \\
& =\frac{\rho_{2}}{\left(\rho_{2}-\rho_{1}\right)\left(1+2\left(\frac{k_{z, \text { botom }}}{k_{z, I}}\right)^{1 / 2}\right)}-\frac{\rho_{1}}{\rho_{2}-\rho_{1}}
\end{aligned}
$$

If $\mathrm{k}_{\mathrm{z}, \mathrm{I}} \gg \mathrm{k}_{\mathrm{z} \text {,bottom }}$ the flow is essentially barotropic:

$$
\lim _{\frac{k_{z, \text { bottom }}}{k_{z, I}} \rightarrow 0}\left(\frac{\Delta h}{\Delta \eta}\right)=1 ; \quad \lim _{\substack{\frac{k_{z, \text { bottom }}}{k_{z, I}} \rightarrow 0\\}}\left(\frac{u_{1}}{u_{2}}\right)=1
$$

For baroclinic situation, values of $\mathrm{k}_{\mathrm{z}, \text { bottom }} / \mathrm{k}_{\mathrm{z}, \mathrm{I}}$ larger than 0 , the ratio $\Delta \mathrm{h} / \Delta \eta$ scales as $\rho /\left(\rho_{2}-\rho_{1}\right)$, where $\rho$ is the average density of the water column:

$$
\left.\frac{\Delta h}{\Delta \eta}\right|_{\frac{k_{z, I}}{k_{z, \text { bottom }}}=a} \approx-\frac{\rho_{2}+\rho_{1}}{\rho_{2}-\rho_{1}} \frac{\sqrt{n}}{(1+2 \sqrt{n})}
$$

For $\mathrm{k}_{\mathrm{z}, \mathrm{I}}=\mathrm{k}_{\mathrm{z} \text {,bottom }}$ and realistic density gradients this ratio is about -300 . As $\mathrm{k}_{\mathrm{z}, \text { bottom }} / \mathrm{k}_{\mathrm{z}, \mathrm{I}}$ grows, the ratio tends to the limit: $-\rho_{1} /\left(\rho_{2}-\rho_{1}\right)$, about -350 in the Arctic Ocean.
However, there is no steady solution for the completely inviscid interface; with no way to transfer stress across the interface, equation (27) indicates:

$$
\lim _{\frac{k_{z, \text { bottom }}}{k_{z, I}} \rightarrow \infty}\left(\frac{u_{1}}{u_{2}}\right)=\infty
$$

\section{Tuning the Model to Observations and a Numerical Model}

[28] For comparison of the simple model with observations, we choose typical parameter values: $\mathrm{f}=1.4 \times 10^{-4}$; $\mathrm{g}=9.8 \mathrm{~m} / \mathrm{s}^{2} ; \rho_{1}=1026 \mathrm{~kg} / \mathrm{m}^{3} ; \rho_{2}=1028 \mathrm{~kg} / \mathrm{m}^{3} ; \rho_{\text {air }}=$ $1.2 \mathrm{~kg} / \mathrm{m}^{3}$; and $\mathrm{c}_{\mathrm{ao}}=1.2 \times 10^{-3}$ We set $\mathrm{R}=1,800 \mathrm{~km}$ (somewhat arbitrarily, to approximate the distance from the North Pole to the Arctic shelf seas).

[29] Choosing values for the vertical viscosity coefficients, $\mathrm{k}_{\mathrm{z}}$, is more difficult. The bottom viscosity coefficient is affected by roughness, bathymetry, tidal amplitude and stratification, all of which vary significantly across the Arctic basin [see, e.g., Weatherly and Martin, 1978]. Empirical values can be estimated if either the depth-scale of the benthic boundary layer or the near-bottom velocity profile is known, using (11) or (15), respectively. However, we are not aware of useful data for either parameter from the deep Arctic. At the pycnocline, $\mathrm{k}_{\mathrm{z}}$ is sensitive to vertical velocity shears, stratification and internal wave fields, which also vary significantly across the Arctic and, again, there is relatively little detailed data for the Arctic. Dewey et al. [1999] estimate the vertical mixing coefficients from profiles of salinity and temperature and find that over the deep Nansen basin, $\mathrm{k}_{\mathrm{z}}$ is between $10^{-4}$ and $10^{-3}$, while over the Siberian continental shelf it is between $10^{-3}$ and $10^{-2}$ (see their Figure 2). Below the pycnocline and above the benthic boundary layer, in our "layer 2", MacDonald and Carmack [1991] get $\mathrm{k}_{\mathrm{z}}$ of about $2.3 \times 10^{-5}$ from fitting ${ }^{14} \mathrm{C}$ profiles. This confirms our assumption that viscous forces are relatively weak in the interior, but does not indicate a value for the bottom boundary layer, which one expects to have a greater vertical transfer of momentum than the interior. Several studies based on observations outside of energetic boundary currents cite a benthic boundary layer thickness between about 10 and 30 meters thick [Elliot, 1984; Saunders, 1983]. Gill [1982, p. 330 ff.] cites a "typical" value of about 10 meters. Weatherly and Martin [1978] use a turbulent closure model to study the benthic boundary layer in detail and get estimates of $\mathrm{k}_{\mathrm{z}}$ there between $10^{-3}$ and $10^{-2}$, depending on the stratification.

[30] In our model $\mathrm{k}_{\mathrm{z}}$ plays the role of transfer coefficient for conducting momentum between model layers and out of the fluid through bottom friction. To map the model to the real Arctic, values should be chosen that reflect diapycnal transfers integrated across the Arctic, including areas of higher diapycnal mixing (continental slopes, ridges, boundary currents). Comparisons of micro-structure and largescale tracer fields from other basins indicate that typical abyssal mixing coefficients seriously underestimate the large-scale average diapycnal mixing [Ledwell et al., 2000].

[31] In light of the diverse physics being parameterized and in the absence of direct measurements, $\mathrm{k}_{\mathrm{z}}$ cannot be 


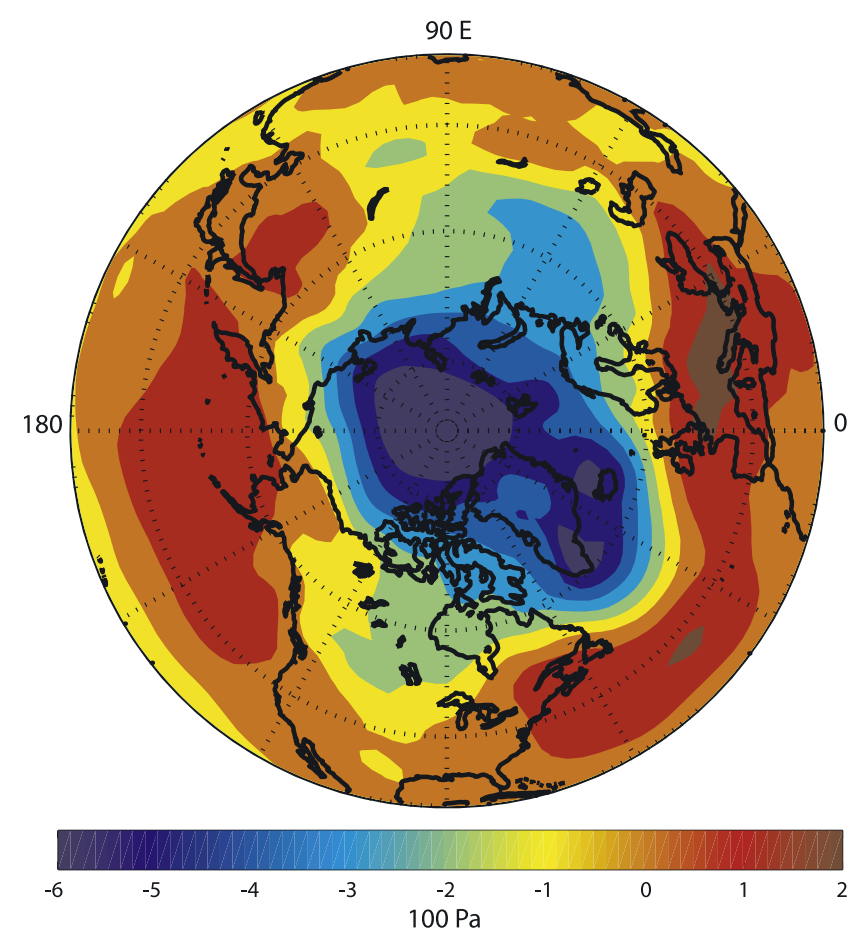

Figure 3. The 1991-1993 average SLP minus the 19791981 average SLP, from the ECMWF Re-Analysis data set.

determined in any firm way. An order of magnitude difference between the interface and bottom values for $\mathrm{k}_{\mathrm{z}}$ implies a value $u_{1}$ about 7.3 times $u_{2}$, a vertical shear that cannot be supported by the tracer data [e.g., Smethie et al., 2000; Newton et al., 2003], or with the existing data from moorings [e.g., Woodgate et al., 1999, 2001; Nost and Isachsen, 2003]. If $\mathrm{k}_{\mathrm{z}, \text { bottom }}$ is set to twice $\mathrm{k}_{\mathrm{z}, \mathrm{I}}$, then the model Layer 1 current is about 3.8 times the Layer 2 current, which is more plausible relationship. With $\mathrm{k}_{\mathrm{z} \text {,bottom }}$ twice $\mathrm{k}_{\mathrm{z}, \mathrm{I}}$, if $\mathrm{k}_{\mathrm{z} \text {,bottom }}$ ranges from 0.001 to 0.01 , the modeled SSH rise corresponding to a $400 \mathrm{~Pa}$ SLP gradient varies between about 0.9 and 0.23 meters, respectively. We can compare this to the output of the Massively Parallel Arctic Ocean Model (MPAOM). The MPAOM is a primitive equation, coupled ice-ocean general circulation model which operates at high resolution (1/6 and 1/12 degree domains) and is forced by the ECMWF Re-Analysis atmospheric data set [Maslowski et al., 2001, 2004; Newton, 2001]. Figure 3 is the difference map between 3-year average SLP fields for those periods from the ECMWF Re-Analysis data set; we take $400 \mathrm{~Pa}$ as a typical value for the pole-to-coast gradient in SLP difference. Figure 4a shows the difference in MPAOM-calculated SSH between 1979 and 1993. The sea-surface salinity and temperature in the MPAOM run has been constrained to stay close to the climatology, so that the interannual SSH changes in the model run are related to surface stress changes, and not to steric heights [Newton, 2001; R. Newton et al., manuscript in preparation. 2006]. SSH has gone up over the shelves, and down over the central Arctic, with a center of action in the Northern Eurasian Basin. Figure $4 \mathrm{~b}$ shows a time series of the SSH in that center (the shaded box in Figure 4a). There is an annual cycle of 1.5 to $2 \mathrm{~cm}$; and there is a decrease of about $11 \mathrm{~cm}$ between 1982 and 1992. Water has been forced from the central basin to the shelves, where the $\mathrm{SSH}$ has risen, especially along the coasts. The total increase in gradient varies along the coastline between about 13 and about $18 \mathrm{~cm}$, supporting a higher value for $\mathrm{k}_{\mathrm{z} \text {,bottom }}$ in our simple model. A $\mathrm{k}_{\mathrm{z} \text {,bottom }}$ of 0.008 results in a bottom boundary layer slightly thicker than 10 meters, below 0.007 corresponds to a bottom boundary layer thinner than 10 meters, the lower limit of observed thicknesses. We settle on $\mathrm{k}_{\mathrm{z}, \text { bottom }}=0.008$ and $\mathrm{k}_{\mathrm{z}, \mathrm{I}}=0.004$, but emphasize that these values are subject to significant uncertainty.

[32] We will force the model with an SLP gradient from the Pole to the coastline, and calculate the sea-surface height (SSH) rise between the pole and the outer boundary of the disk. As a first estimate of the SLP change between relatively anticyclonic and relatively cyclonic circulations, we take the difference between two three-year periods: 1979-1982 and 1991-1993. These are not the most extreme periods, in terms of the cyclonicity of the Arctic winds, but they display a significant shift in the wind regimes and correspond to detailed model output against which we will validate our results.

[33] The perennial sea-ice cover has so far made accurate SSH measurements over the central Arctic difficult, whether from satellite-based altimeters or moorings. However, there is data for SSH at the outer boundary of the Arctic, from coastal tide gauges. Figure 5 shows the locations of the stations used in this study. The data are publicly available from the PSMSL website, http://www.pol.ac.uk/psmsl, and have been described by Proshutinsky et al. [2001]. All tide gauge time series in the Arctic have gaps. For this analysis we accepted monthly-average data for each month which had at least 20 useful daily values. We eliminated tide gauges that are shielded from the open ocean (estuarine locations and locations in the interior of the Canadian Arctic Archipelago); and we eliminated gauges which were missing 100 months in the period between 1949 and 2001. This resulted in 30 useful gauges, out of 152 PSMSL-catalogued gauges within the Arctic, all of them located in the Russian sector. Even within this set, for some years between 1949 and 2001 the data is sparse spatially. However, between the years 1953 and 1992 there are useful data for all months from at least 27 gauges, and we focus on those 4 decades to tune and validate the model.

[34] Tide gauge data reflect two types of anomalies: steric height anomalies from changes in the mean density of the water column at the tide gauge; and convergence of water toward (or away from) the tide gauge location. The latter can be decomposed into convergence due to changes in air pressure, that from addition of mass (e.g., from increased river runoff) and that due to the wind-driven circulation. It is the annual average wind-driven SSH anomaly (Ekman transport) that we would like to consider. To eliminate the main steric height anomalies, associated with the seasonal cycle, we have smoothed the data with a 365-day runningmean filter. To eliminate the direct sea-level pressure ("inverse barometer") effect we have used global NCEP SLP fields to calculate the sea-surface displacement due to surface pressure changes at each tide gauge location, and have subtracted these displacements from the monthly-average tide gauge measurements. The adjustment of SSH to SLP is 

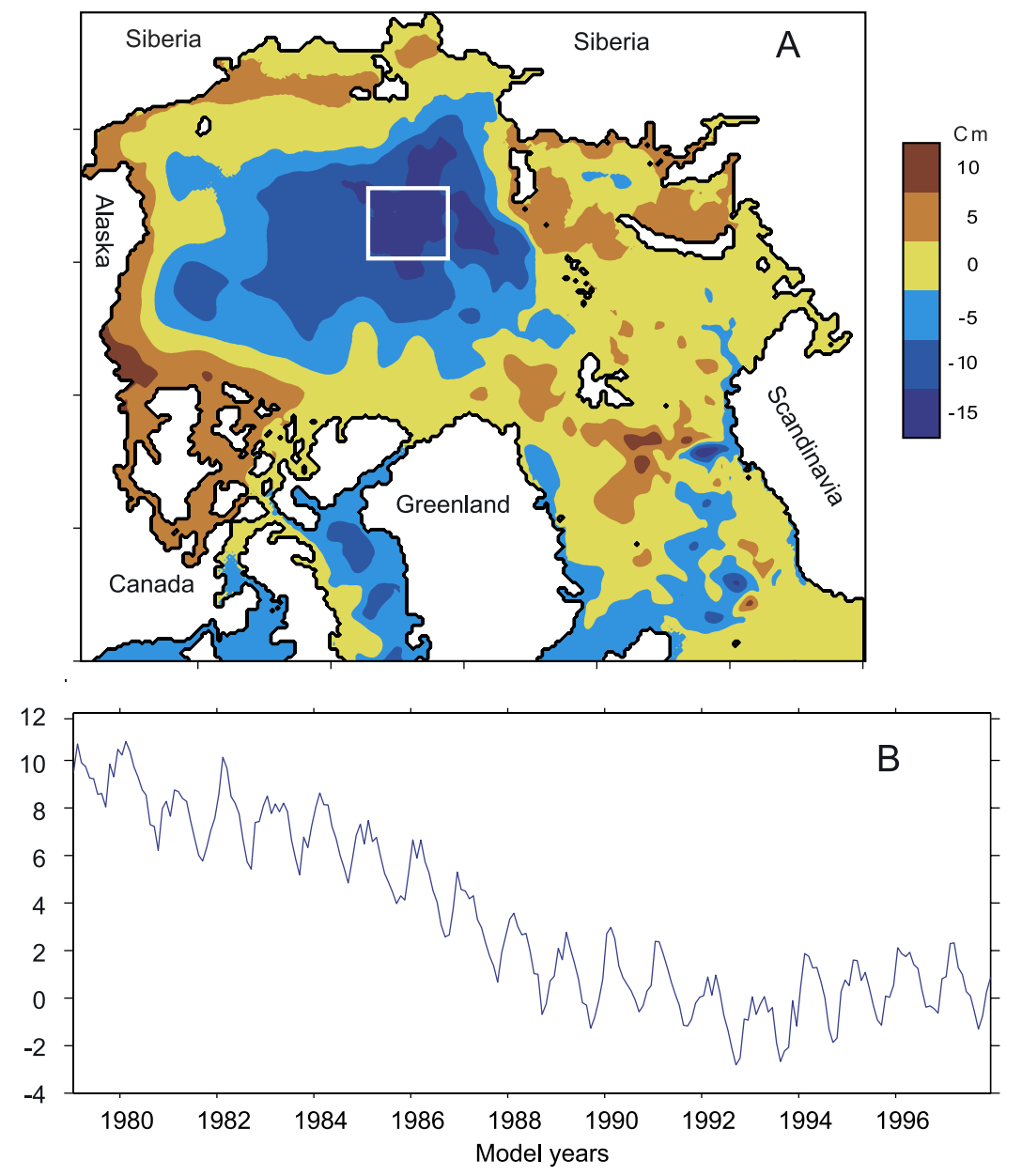

Figure 4. Sea-surface height (SSH) fields from the NAMES general circulation model. (a) Difference between the annually averaged fields for 1979 and 1990. (b) Time series of NAMES SSH near the North Pole (white box in Figure 4a). Heights are in $\mathrm{cm}$.

mainly through gravity waves, which are fast compared with the changes in SLP and with seasonal-to-decade timescales. Therefore we have calculated the instantaneous adjustment of the SSH to the SLP, ignoring the adjustment times.

[35] To compare tide gauge heights with model predictions covering a time-series of the observational record, we used the NCEP re-analysis sea-level pressure data. For each tide gauge location we calculated the difference between the SLP interpolated to the tide gauge location and the SLP over the central Arctic, averaged over the region from $87.5 \mathrm{~N}$ to the North Pole. We used equation (36), with R set to the actual distance between each tide gauge and the North Pole, to predict the SSH tilt from the Pole to each tide gauge for each day between 1949 and 2001, and averaged the SSH anomaly at the coast for all tide gauge locations shown in Figure 5.

[36] The Arctic coasts experience massive river runoff and sea-ice melt in the early summer, and freezing temperature with ice formation in the winter. The result is a large annual cycle in steric height [Proshutinsky et al., 2004]. To eliminate this cycle and focus on the interannual variability we smoothed the data with a 365-day running mean filter. There is also a trend in the tide gauge heights, to which both secular changes in water density and ongoing glacial rebound contribute [Proshutinsky et al., 2004]. However, these changes are small, on the order of $0.2 \mathrm{~cm}$ per annum, compared with the signals considered in this study, and we do not discuss them further.

[37] Figure 6a compares the observed tide gauge sea surface heights with the model predictions. Both time series have been filtered with a one year moving average and the tide gauge data have been averaged spatially among all gauges with sufficient temporal coverage (at least 27 tide gauges for each month between 1952 and 1992). The correlation coefficient between the two time series between 1953 and 1992 is 0.62 , significant at the $99 \%$ confidence level. The model and the data diverge sharply in 1957, but otherwise most of the large SSH anomalies seen in the average tide gauge heights are picked up by the model. Since the model predicts SSH tilt at steady state, whereas the real Arctic is constantly adjusting to the changing winds, the model will overshoot the observations at the peaks and troughs of SLP gradient. The degree of overshoot will be controlled by the bottom and interface viscosities. A more "slippery" system will overshoot farther. Figure $6 \mathrm{~b}$ shows the variation of the SSH at the model boundary for a 400 millibar SLP gradient 


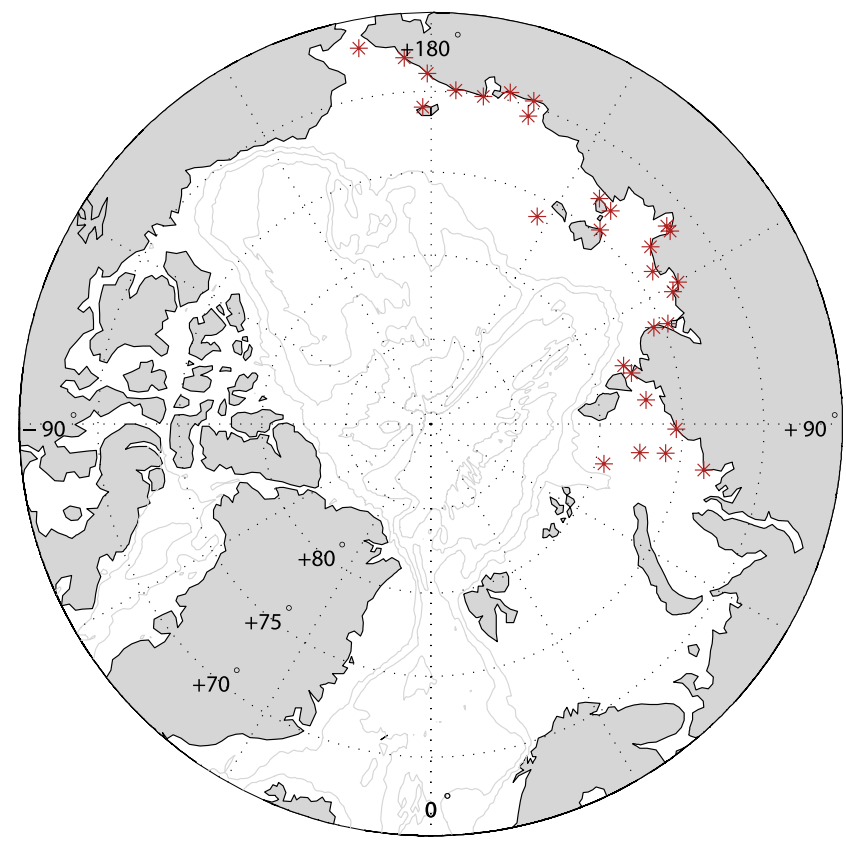

Figure 5. Locations of the tide gauges used for data comparison between observed sea-surface heights and model predictions.

between the coastline and the North Pole. In Figure 6b, we set $\mathrm{k}_{\mathrm{z} \text {,bottom }}$ to 0.008 and let $\mathrm{k}_{\mathrm{I}}$ vary. In calculating the interface depth below we use the high value of 0.004 for $k_{z, I}$ because it is "conservative" in the sense that a lower $\mathrm{k}_{\mathrm{z}}$ would result in larger anomalies of both SSH and pycnocline tilt, which will lead to larger freshwater outflows.

[38] In the analytic model, the SLP anomalies enter through their relation to the surface wind-stress curl; and the patterns are taken to be completely symmetric in the zonal direction. We test the robustness of the mechanism by comparing the data with other proxies for the average curl of the large-scale wind-stress fields. Figure 7 shows the time series of average tide gauge height anomalies from the Russian Arctic in black along with 3 atmospheric variables.

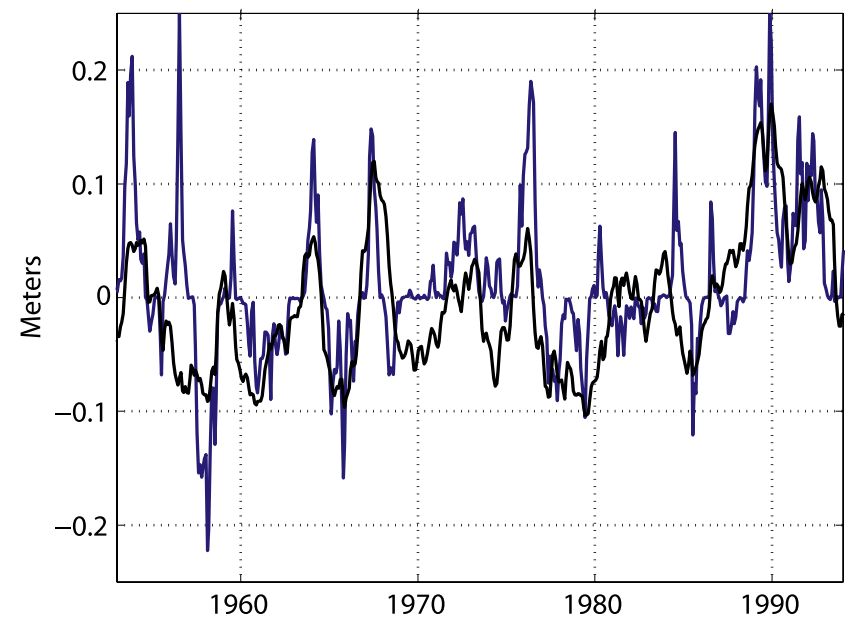

Figure 6a. Model prediction of sea-surface height anomaly at the boundary (blue) and the average of the tide gauge anomalies (black). Both time series are in meters. Correlation between the two time series is 0.624 .

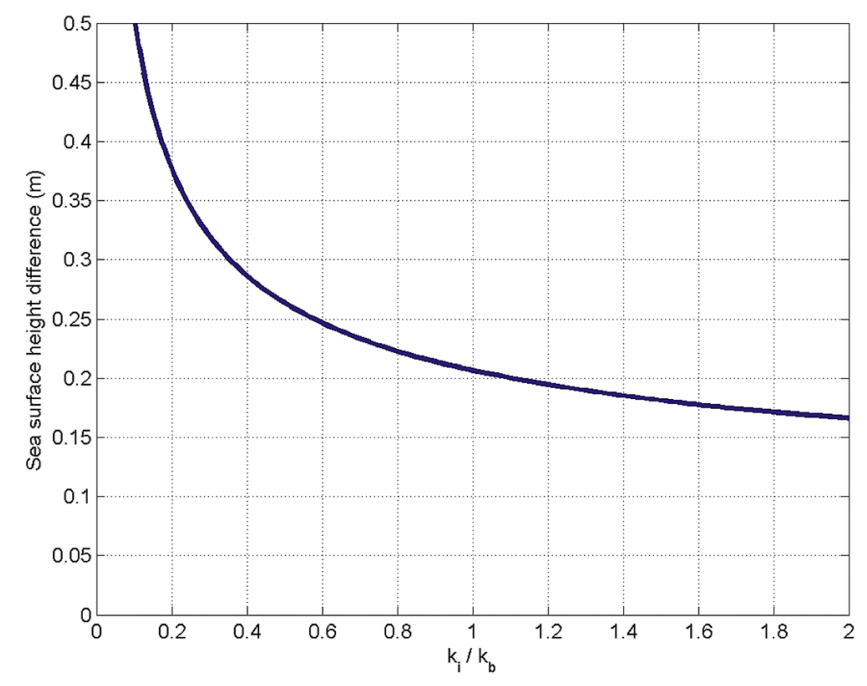

Figure 6b. Model SSH difference, center to outer wall, as a function of the ratio of interface-to-bottom viscosities, assuming a $400 \mathrm{mb}$ SLP difference and a bottom viscosity of 0.008 .

All time series have been normalized, using each series' mean and standard deviation, and then filtered with a one year running mean. The correlations between the tide gauge time series and these indices of large-scale wind stress patterns are greater than 0.6 for all the series, and are significant at the 99 percent confidence level. So the Arctic SLP, and the vorticity input at the surface are significantly correlated with the spatially averaged tide gauge heights, a measure of the SSH excursion along the coasts. All three are correlated with the NAO, a principle index of large-scale Northern Hemisphere atmosphere variability.

\section{Model Prediction of Freshwater Outflow}

[39] Equation (37) predicts the depth of the pycnocline as a result of changes in the wind forcing. Except in the barotropic case, the sign of the interface tilt, $\Delta \mathrm{h}$, is opposite to the sign of the SSH tilt and scales as the inverse of the

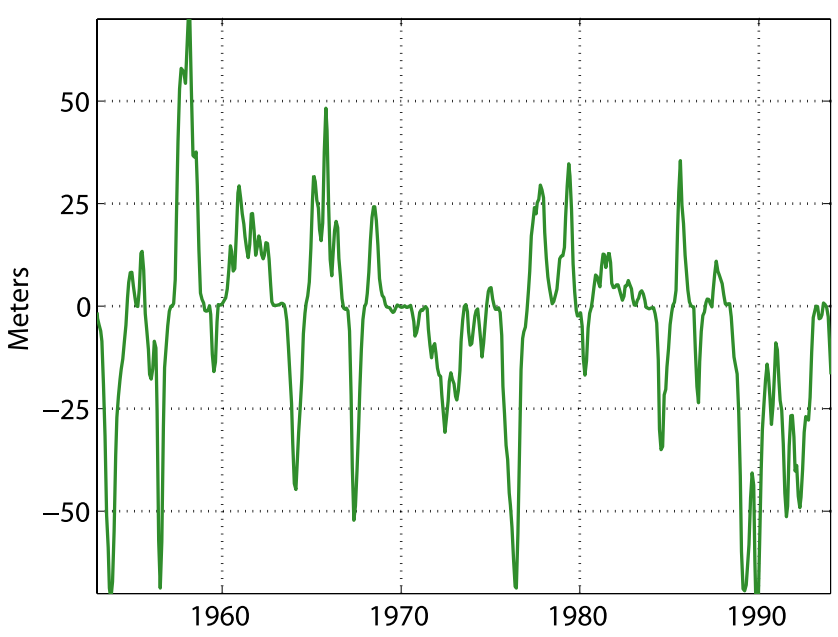

Figure 6c. Model pycnocline depth anomaly (h) at the boundary of the model basin. 


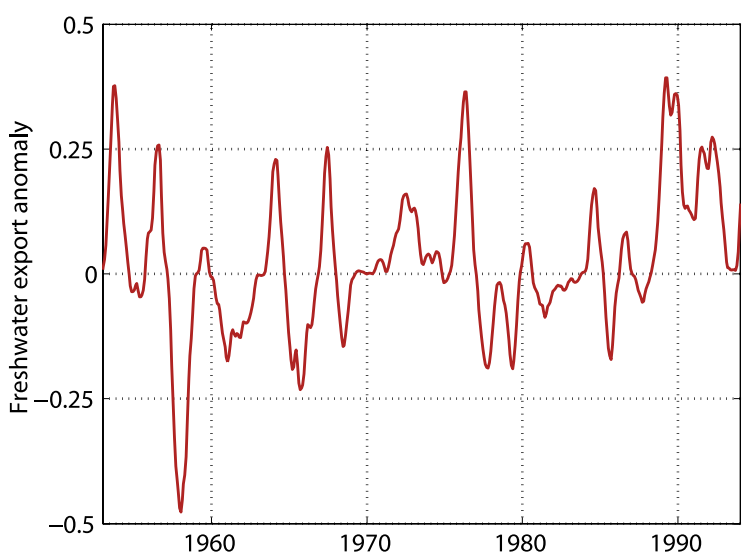

Figure 6d. Freshwater export anomaly, expressed as a fraction of the climatological mean, implied by the pycnocline depth anomaly at the boundary of the model basin.

density anomaly. Figure 6c shows a time series of pycnocline depth anomalies, forced by the annular mode geostrophic winds, assuming that the base of the pycnocline at the outer edge of the basin is $200 \mathrm{~m}$. Thus, for a SSH rise of $20 \mathrm{~cm}$, the pycnocline at the outside of the model disk can deepen by about $60 \mathrm{~m}$. Following the lead of Stigebrandt [1981], Bjork [1989], and Hunkins and Whitehead [1992], we assume that the exchange between the Arctic and the North Atlantic through Fram, Nares and McClure straits is in geostrophic balance. Then the width of the outflow scales with the Rossby radius, $\left(\mathrm{g}^{\prime} \mathrm{H}_{1}\right)^{1 / 2} / \mathrm{f}$, and its velocity with $\left(\mathrm{g}^{\prime} \mathrm{H}_{1}\right)^{1 / 2}$, so that the volume flux of Polar Water through the straits will be proportional to the square of the depth of the pycnocline:

$$
Q_{P W}=\gamma \frac{g^{\prime}}{f} H_{1}^{2}
$$

where $\gamma$ is a non-dimensional parameter. Theoretically, $\gamma=0.5$ for a baroclinic outflow over a motionless bottom layer; it is taken by Stigebrandt to be about one to account for the 3 main straits (Fram, Nares and McClure Straits). Hunkins and Whitehead estimate $\gamma$ at about 0.156 for a flat-bottom lock-exchange model of Fram Strait.

[40] We are interested in the flux of buoyancy from the Arctic to the North Atlantic in the form of a freshwater excess, relative to the salinity of the North Atlantic surface water just south of the straits. The freshwater flux will be approximately:

$$
Q_{\text {fresh }}=\frac{S_{A}-S_{1}}{S_{1}} \frac{\gamma g^{\prime}}{f} H_{1}^{2}
$$

where $\mathrm{S}_{\mathrm{A}}$ is the salinity of North Atlantic surface water, and $\mathrm{S}_{1}$ is the salinity of the outflowing Polar Water. To get a sense of scale, if $\gamma=1$, then with $\mathrm{g}^{\prime}=0.02, \mathrm{H}_{1}=200 \mathrm{~m}$ and $\left(\mathrm{S}_{\mathrm{A}}-\mathrm{S}_{1}\right) / \mathrm{S}_{1}=0.028$, the Polar Water outflow estimate is about $2.35 \mathrm{~Sv}\left(1 \mathrm{~Sv}=10^{6} \mathrm{~m}^{3} / \mathrm{s}\right)$ and the "excess" liquid freshwater export, relative to North Atlantic salinity, is approximately $2000 \mathrm{~km}^{3}$ per year. These values compare reasonably well with geostrophic calculations in Fram Strait
[Stigebrandt, 1981; Hunkins and Whitehead, 1992], though they somewhat underestimate the total Polar Water outflow and overestimate the freshwater excess as measured recently by moorings [Holfort and Hansen, 2004]. To focus on the variability implied by the model, and without a climatology against which to assess changes, we consider the anomaly as a fraction of an (as yet poorly understood) mean value. Assuming the salinities and densities of Polar and Atlantic waters to remain constant, the ratio of the freshwater outflow to the climatological value will be (using (37) to express $\Delta \mathrm{h})$ :

$$
\begin{aligned}
\frac{\Delta Q_{\text {fresh }}}{Q_{\text {fresh }}} & =\frac{\left(H_{1}+\Delta h\right)^{2}}{H_{1}^{2}} \\
& =\frac{\left(H_{1}+\frac{c_{a o}}{k_{z, \text { botom }}(2)}\left(\frac{1}{\rho_{1}}-\frac{1}{\rho_{2}}\left(1+2\left(\frac{k_{z, \text { botom }}}{k_{z, I}}\right)^{1 / 2}\right)\right)\left(\frac{2}{f}\right)^{3 / 2} \frac{\cos (\alpha)}{g^{\prime} R \rho_{\text {air }}} \delta p|\delta p|\right)^{2}}{H_{1}^{2}}
\end{aligned}
$$

[41] Figure 6d shows the modeled freshwater outflow anomaly, as a fraction of the long-term average, for $\mathrm{H}_{1}=$ $200 \mathrm{~m}$. To get volume estimates for the anomalies, the climatological mean freshwater export is required. However, the observations are sparse, and their temporal variation is large. The main outflows for freshwater from the Arctic are Lancaster, Jones and Smith sounds in the Canadian Arctic Archipelago and Fram Strait, east of Greenland. Prinsenberg and Hamilton [2005] estimate the freshwater outflow through Lancaster Sound to be about 1,100, 2,300 and $2,400 \mathrm{~km}^{3}$ for three years between fall of 1998 and fall of 2001. Meredith et al. [2001] estimate the summer outflows of meteoric water through Fram Strait at $3680 \mathrm{~km}^{3} / \mathrm{yr}$ and $2000 \mathrm{~km}^{3} / \mathrm{yr}$ for 1997 and 1998, respectively. Meteoric water is only an approximate estimate of the total liquid freshwater flux, since is does not include the sea-ice melt contribution. Nor do Meredith et al. account for variations due to local winds, which peak in the fall and winter, and diminish in the summer. In addition, there are not yet useful

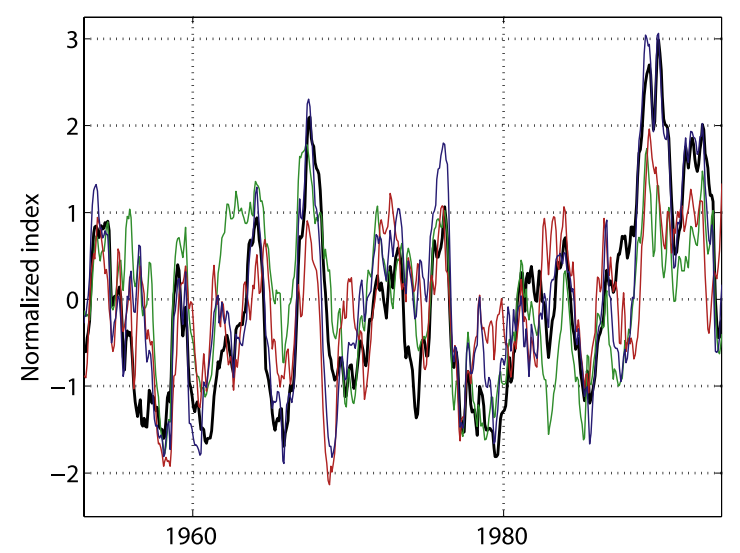

Figure 7. Normalized anomaly time series of average tide gauge $\mathrm{SSH}$ with the inverse-barometer effect removed (black). NAO index (red) (ftp://ftpprd.ncep.noaa.gov/pub/ $\mathrm{cpc} / \mathrm{wd} 52 \mathrm{dg} / \mathrm{data} /$ indices/tele_index.nh). Negative of average SLP from 80-90 N (blue). Vorticity of the 10-m winds averaged over 65-90 $\mathrm{N}$ (green). Each time series is smoothed with 1 -year running mean. 
estimates of the freshwater flux through Smith and Jones sound. The average for the sum of the Lancaster Sound freshwater flux and the Fram Straits meteoric water flux is about $4,800 \mathrm{~km}^{3}$. Widell et al. [2003] estimate the sea-ice export through Fram Strait as $2,400 \mathrm{~km}^{3}\left( \pm 480 \mathrm{~km}^{3}\right)$ for the $1990 \mathrm{~s}$, and we recall that the estimated annual mean input of freshwater to the Arctic from southern latitudes, which should be balanced by the sum of liquid freshwater and ice export is about $7,800 \mathrm{~km}^{3}$. Thus, while the long-term mean liquid freshwater export has not been measured, we believe that it must be between about 3,000 and $5,000 \mathrm{~km}^{3}$. This range would correspond to cycles in the modeled freshwater outflow with trough-to-peak amplitudes of between 1,800 and $3,000 \mathrm{~km}^{3}$ on timescales of about 5 years. The midpoint, $2,400 \mathrm{~km}^{3}$, is a volume of freshwater roughly equivalent to the Great Salinity Anomaly that appeared in the late 1960s.

\section{Discussion}

[42] Energy dissipation in the real Arctic is obviously very complex, and is not resolved by the simple model we present above. The Arctic basin is not bounded by vertical walls, but by a ring of wide continental shelves, each with a distinct and complex geometry. The basin bottom is not flat but is subtended by long ocean ridges and corrugated at a variety of important length scales. Pack ice mediates the transmission of stress from the atmosphere to the water and, especially in winter, a fraction of surface stress is absorbed in ice ridging and internal ice stress. As a result, a combination of complicated processes is at work, including: friction with the corrugated bottom of the ice-cover; mixing of momentum from the "spin down" of eddies which have detached from shelf- or continental-slope currents; and transfer of momentum through breaking of internal waves at the pycnocline. We view the bottom and interface friction of the simple model as proxies for the panoply of basindependent dissipative mechanisms. Our essential contention is that the dissipation, regardless of the mechanisms involved, will depend on the strength of the geostrophic currents which, in turn, set the size of the surface and interface height anomaly fields. Thus, although the model simplifies the actual dissipative mechanisms it captures the principal energy balances well enough to give a quantitative fit with estimates from observations and more realistic general circulation models.

[43] Another simplification in our calculation is that we treat the anomalous forcing, the annular mode, as independent of the mean surface stress pattern. This is equivalent to assuming that the coupling of the wind and surface ocean is linear, whereas it is approximately quadratic. Disregarding interaction between the annular mode and the rest of the wind field overly emphasizes the annular nature of the surface stress; the real-world response to the annular mode will include a longitudinal asymmetry that we do not calculate here. Nonetheless, the model does seem to capture a significant fraction of the response. This is first of all an expression of the fact that the anomalies associated with the NAM are relatively large. Interannual-to-decadal variations in SLP gradients associated with the NAM have amplitudes of several millibars, similar to the scale of spatial gradients in the climatological SLP fields. (See the technical reports from the International Arctic Buoy Program [e.g., Rigor and Heiberg, 1997].) Thus, in the quadratic coupling used in equation (33) the square of the SLP gradient associated with the NAM will not be dominated by the interaction of the NAM with the rest of the SLP field. Secondly, as noted above, the geometry of the Arctic allows for the excitation of relatively annular motions in the ocean. Coastal Kelvin waves and topographic Rossby waves can circumnavigate the Arctic quickly, whereas planetary Rossby waves propagate very slowly. The fortuitous alignments of the Arctic shelf-break and coastlines with isolines of the NAM SLP pattern allow the ocean to respond readily to the annular mode, in the fashion described above.

[44] Finally, we make no claims that divergence associated with the annular mode is the only mechanism affecting the sea-surface height and the depth of the pycnocline in the Arctic. Non-annular wind patterns, density changes, direct affects of air pressure (the "inverse barometer"), and glacial rebound all play a role. However, it does appear that on interannual to decadal timescales the annular mode forcing is at least capable of exerting a dominant influence. Proshutinsky et al. [2004] analyzed the secular trend in SSH from Siberian tide gauges over about the same period as we discuss in this paper. They found that winds do not dominate, playing a role on par with glacial rebound, secular trends in density, and direct air pressure (inverse barometer) effects. This is not a contradiction with the results shown in our Figure 6a; the secular trend in $\mathrm{SSH}$ from Proshutinsky et al. is about $.18 \mathrm{~cm}$ per year while the standard deviation of interannual tide gauge heights is about $6 \mathrm{~cm}$. While the winds may dominate SSH variability on interannual timescales, their residual effect on interdecadal scales is much diminished.

\section{Conclusion}

[45] The simple model described above shows that in the Arctic the first order response of the ocean to annular mode forcing is a change in the average meridional gradients of the sea-surface height and pycnocline depth, and a corresponding increase or decrease of the eastward flow around the basin. In the high-resolution NAMES, the currents associated with a positive (or negative) shift in the NAM draw Atlantic water more (or less) quickly into the Canadian side of the Arctic [Maslowski et al., 2000]. They also redistribute freshwater plumes from the shelf seas, and play an important role in modulating the export of buoyant Polar Water to the Nordic seas and Baffin Bay [Newton, 2001; Maslowski et al., 2004; Schlosser et al., 2002; R. Newton et al., manuscript in preparation, 2006]. This mechanism is consistent with the phenomena explored by Proshutinsky and coauthors [e.g., Proshutinsky and Johnson, 1997; Dukhovskoy et al., 2004]. However, we do not see their 14-year timescale in the tide gauge data, nor do we see evidence for a coupled mode local to the Arctic region. The correlation between the several indices of Figure 7 indicates that the Arctic SSH tilt is part of a mode of variability that involves much of the Northern Hemisphere atmosphere. Even without understanding the roots of such variability, the links discussed above may have broader diagnostic value. In particular, shifts in the sea-level pressure, geopotential height of the atmosphere, or coastal SSH might be used to diagnose shifts 
in some of the large-scale currents over the Arctic Basin and freshwater export from the Arctic to the Nordic seas and Baffin Bay. Assuming the outflow amplitude to be controlled by geostrophy, the results above imply that large-scale wind patterns such as those associated with the NAO or the AO indexes, may significantly modulate the outflow of buoyancy from the Arctic to the North Atlantic.

[46] Probably the most serious model simplifications are the exclusion of bathymetry, which cuts the Arctic into two major sub-basins (Eurasian and Canadian) and then each of these into two or three minor basins (Nansen, Amundsen, Makarov, Canada), and the simplification of the atmospheric forcing. These excluded dynamics would alter the simple $\mathrm{SSH}$, pycnocline and circulation modes. However, the extreme simplicity of our model is useful in understanding the basic dynamics we describe, while comparison with data demonstrates that this simple approach has some relevance to the real Arctic Ocean.

\section{References}

Aagaard, K., and E. C. Carmack (1989), The role of sea ice and other freshwater in the Arctic circulation, J. Geophys. Res., 94(C10), 14,48514,498 .

Bjork, G. (1989), A one-dimensional time-dependent model for the vertical stratification of the upper Arctic Ocean, J. Phys. Oceanogr., 19(1), 52-67.

Dery, S., and M. K. Yau (2002), Large scale mass balance effects of blowing snow and surface sublimation, J. Geophys. Res., 107(D23), 4679, doi:10.1029/2001JD001251.

Dewey, R., R. Muench, and J. Gunn (1999), Mixing and vertical heat flux estimates in the Arctic Eurasian Basin, J. Mar. Syst., 21, 199-205.

Dukhovskoy, D. S., M. A. Johnson, and A. Proshutinsky (2004), Arctic decadal variability: An auto-oscillatory system of heat and fresh water exchange, Geophys. Res. Lett., 31, L03302, doi:10.1029/2003GL019023.

Elliot, A. J. (1984), Measurements of the turbulence in an abyssal boundary layer, J. Phys. Oceanogr., 14, 1779-1784.

Environmental Working Group (EWG) (1998), Arctic Ocean Atlas, v.1.0, Natl. Snow and Ice Data Cent., Boulder, Colo.

Gill, A. (1982), Atmosphere-Ocean Dynamics, Elsevier, New York.

Groves, D. G., and J. A. Francis (2002), Moisture budget of the Arctic atmosphere from TOVS satellite data, J. Geophys. Res., 107(D19), 4391, doi:10.1029/2001JD001191.

Gudkovich, Z. M. (1961), Relation of the ice drift in the Arctic Basin to ice conditions in Soviet Arctic seas (in Russian), Tr. Okeanogr. Kom. Akad. Nauk SSSR, 11, 14-21.

Holfort, J., and E. Hansen (2004), Freshwater transport within the East Greenland Current, paper presented at Clivar 2004, Baltimore, Md. (Available at http://www.clivar2004.org/electronic\%20posters/ocean/ 5Holfort.J.OC169.pdf).

Hunkins, K., and J. A. Whitehead (1992), Laboratory simulation of exchange through Fram Strait, J. Geophys. Res., 97(C7), 11,299-11,322.

Ledwell, J. R., E. T. Montgomery, K. L. Polzin, L. C. St. Laurent, R. W. Schmitt, and J. M. Toole (2000), Evidence for enhanced mixing over rough topography in the abyssal ocean, Nature, 403, 179-182.

MacDonald, R. W., and E. C. Carmack (1991), Age of Canada Basin deep water: A way to estimate primary production for the Arctic Ocean, Science, 254, 1348-1350.

Maslowski, W., R. Newton, P. Schlosser, B. Semtner, and D. Martinson (2000), Modeling recent climate variability in the Arctic Ocean, Geophys. Res. Lett., 27, 3743-3746.

Maslowski, W., D. Marble, W. Walczowski, and A. J. Semtner (2001), On the large-scale shifts in the Arctic Ocean and sea-ice conditions during 1979-98, Ann. Glaciol., 33, 545-550.

Maslowski, W., D. Marble, W. Walczowski, U. Schauer, J. L. Clement, and A. J. Semtner (2004), On climatological mass, heat, and salt transports through the Barents Sea and Fram Strait from a pan-Arctic coupled iceocean model simulation, J. Geophys. Res., 109, C03032, doi:10.1029/ 2001JC001039.

Meredith, M., K. Heywood, P. Dennis, L. Goldson, R. White, E. Fahrbach, U. Schauer, and S. Osterhus (2001), Freshwater fluxes through the western Fram Strait, Geophys. Res. Lett., 28(8), 1615-1618.

Newton, R. (2001), River runoff into the Arctic Ocean: Results from a highresolution general circulation model and model-data comparisons, Ph.D. thesis, Columbia Univ., New York.
Newton, R., P. Schlosser, W. Smethie, B. Ekwurzel, and S. Khatiwala (2003), Arctic Ocean tracer datasets at the LDEO Environmental Tracer Laboratory, paper presented at SEARCH Science Meeting, Oct.

Nikiforov, Y. G., Y. V. Belyshevsky, and N. I. Blinov (1966), Structure of water masses in the eastern part of the Arctic Basin, Oceanol. USSR, 6(1), 59 , ff.

Nikiforov, Y. G., Y. I. Chaplygin, and A. O. Shpaykhen (1969a), Atmospheric circulation and convection in Arctic Seas, Oceanol. USSR, 9(3), 341, ff.

Nikiforov, Y. G., Y. I. Chaplygin, and A. O. Shpaykhen (1969b), Pressure systems and dynamic processes in Arctic Seas, Oceanol. USSR, 9(5), 633, ff.

Nost, O. A., and P. E. Isachsen (2003), The large-scale, time-mean ocean circulation in the Nordic Seas and Arctic Ocean estimated from simplified dynamics, J. Mar. Res., 61, 175-210.

Prinsenberg, S. J., and J. Hamilton (2005), Monitoring the volume, freshwater and heat fluxes passing through Lancaster Sound in the Canadian Arctic Archipelago, Atmos. Ocean, 43(1), 1-22.

Proshutinsky, A., and M. Johnson (1997), Two circulation regimes of the wind driven Arctic Ocean, J. Geophys. Res., 102(C11), 12,493-12,514. Proshutinsky, A., V. Pavlov, and R. Bourke (2001), Sea level rise in the Arctic Ocean, Geophys. Res. Lett., 28, 2237-2240.

Proshutinsky, A., M. Ashik, E. N. Dvorkin, S. Hakkinen, R. A. Krishfield, and W. R. Peltier (2004), Secular sea level change in the Russian sector of the Arctic Ocean, J. Geophys. Res., 109, C03042, doi:10.1029/ 2003JC002007.

Rigor, I., and A. Heiberg (1997), International Arctic Buoy Program Data Report 1995 Data Report, APL-UW TM 4-97.

Roach, A. T., et al. (1995), Direct measurements of transport and water properties through the Bering Strait, J. Geophys. Res., 100(C9), 18,443$18,457$.

Saunders, P. M. (1983), Benthic observations on the Madeira Abyssal Plain-Currents and dispersion, J. Phys. Oceanogr., 13(8), 1416-1429.

Schlosser, P., R. Newton, B. Ekwurzel, S. Khatiwala, R. Mortlock, and R. G. Fairbanks (2002), Decrease of river runoff in the upper waters of the Eurasian Basin, Arctic Ocean between 1991 and 1996: Evidence from $\delta 180$ data, Geophys. Res. Lett., 29(9), 1289, doi:10.1029/ $2001 \mathrm{GL} 013135$

Shiklomanov, I. A., A. I. Shiklomanov, R. B. Lammers, B. J. Peterson, and C. J. Vorosmarty (2000), The dynamics of river water inflow to the Arctic Ocean, in The Freshwater Budget of the Arctic Ocean, Springer, New York.

Smethie, W., P. Schlosser, G. Bonisch, and T. S. Hopkins (2000), Renewal and circulation of intermediate waters in the Canadian Basin observed on the SCICEX 96 cruise, J. Geophys. Res., 105(C1), 1105-1121.

Stigebrandt, A. (1981), A model for the thickness and salinity of the upper layer in the Arctic Ocean and the relationship between the ice thickness and some external parameters, J. Phys. Oceanogr., 11(10), 1407-1422.

Swift, J. H., E. P. Jones, K. Aagaard, E. C. Carmack, M. Hingston, R. W. Macdonald, and F. A. McLaughlin (1997), Waters of the Makarov and Canada Basins, Deep Sea Res., 44(8), 1503-1529.

Treshnikov, A. F. (1971), Oceanological investigations in the Arctic and Antarctic during the Soviet regime, Oceanol. USSR, 11(5), 684, ff.

Weatherly, G. L., and P. J. Martin (1978), On the structure and dynamics of the oceanic bottom boundary layer, J. Phys. Oceanogr., 8, 557-570.

Weingartner, T. J., et al. (1999), Siberian Coastal Current: A wind- and buoyancy-forced Arctic coastal current, J. Geophys. Res., 104(C12), $29,697-29,713$

Widell, K., S. Osterhus, and T. Gammelsrod (2003), Sea ice velocity in the Fram Strait monitored by moored instruments, Geophys. Res. Lett. 30(19), 1982, doi:10.1029/2003GL018119.

Woodgate, R. A., and K. Aagaard (2005), Revising the Bering Strait freshwater flux into the Arctic Ocean, Geophys. Res. Lett., 32, L02602, doi:10.1029/2004GL021747.

Woodgate, R. A., E. Fahrbach, and G. Rohardt (1999), Structure and transports of the East Greenland Current at $75^{\circ} \mathrm{N}$ from moored current meters, J. Geophys. Res., 104(C8), 18,059-18,072.

Woodgate, R. A., K. Aagaard, R. D. Muench, J. Gunn, G. Bjørk, B. Rudels, A. T. Roach, and U. Schauer (2001), The Arctic Ocean boundary current along the Eurasian slope and the adjacent Lomonosov Ridge: Water mass properties, transports and transformations from moored instruments, Deep Sea Res., Part I, 48, 1757-1792.

Yang, D. Q. (1999), An improved precipitation climatology for the Arctic Ocean, Geophys. Res. Lett., 26(11), 1625-1628.

M. A. Cane, B. Newton, P. Schlosser, and L. B. Tremblay, LamontDoherty Earth Observatory of Columbia University of New York, Geochemistry 63, P.O. Box 1000, Palisades, NY 10964-8000, USA. (bnewton@1deo.columbia.edu) 